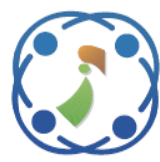

\title{
Improvement of Power Quality Injected into the Grid by Using a FOSMC-DPC for Doubly Fed Induction Generator
}

\author{
Mohamed Amine Beniss ${ }^{1 *}$ \\ Hassan El Moussaoui ${ }^{1}$ \\ Hassane El Markhi ${ }^{1}$ \\ Tijani Lamhamdi ${ }^{1}$ \\ ${ }^{1}$ Electrical Department, Intelligent systems, geosources and renewable energy laboratory, Faculty of Sciences and \\ Technologies, Sidi Mohamed Ben Abdellah University, Fez, Morocco \\ * Corresponding author's Email: Mohamedamine.beniss@usmba.ac.ma
}

\begin{abstract}
This research work deals with the design of a direct power control strategy (DPC) based on the fractionalorder sliding mode (FOSMC) theory for the doubly fed induction generator (DFIG). The novelty of this paper is the use of proportional derivative (PD) fractional order sliding surface that is constructed using Riemann-Liouville fractional derivative and its accurate representation with a transfer function. This make the whole control strategy simpler and more accurate. Also the study of the quality of the current injected into the grid is performed. The stability of DFIG is guaranteed by means of the Lyapunov function. In order to optimize the amount of electrical energy captured from the wind, the MPPT (Maximum Power Point Tracking) technique is adopted. The proposed controller forces the system to track the desired values of active and reactive powers. In addition, power ripples are restrained even if the DFIG is subjected to disturbances and parameter variations. Furthermore, a comparative study is conducted between the developed controller and other nonlinear methods that exist in the literature. The results obtained, under different wind profiles, confirm its robustness and superiority in terms of performance and quality of power injected into the grid. In terms of THD, our control strategy does not exceed $1.31 \%$, on the contrary, the fuzzy logic DTC which is developed recently reaches $2.81 \%$.
\end{abstract}

Keywords: Doubly fed induction generator (DFIG), Sliding mode control (SMC), Direct power control (DPC), Fractional order calculus, MPPT.

\section{Introduction}

The international community continues to show a keen interest in renewable energy. The depletion of fossil fuels, the greenhouse effect, and pollution are the leading causes that have raised this global concern. Also, economic and demographic growths have increased the demand for energy.

Nowadays, wind energy becomes a kind of promising renewable source of clean energy. The World Wind Association forecast that the wind installed capacity can reach $1600 \mathrm{GW}$ by the end of 2030 [1]. Particularly, in morocco, the goal has been set to $2 \mathrm{GW}$ in 2020 [2]. Several facts justify the importance given to wind energy among other renewable energies: it is cost-effective, more reliable, and wind farms can be either onshore or offshore.

The variable nature wind speed makes it challenging to convert aerodynamic energy into electricity exploitable directly by the grid. Static converters are used as an interface that allows the synchronization and adaptation of produced energy. To reduce the cost of these converters, modern farms rely on DFIG wind systems (Fig. 1). Indeed, the rotor is connected to the grid through a back-to-back converter. While only $30 \%$ at maximum of produced energy can transit via the rotor, the extra cost of the converter is saved [3].

The DFIG functions in two modes [4]; the first one is the sub-synchronous mode in which the rotor speed is below the synchronous speed. In this case, a portion of the energy produced is consumed by the 


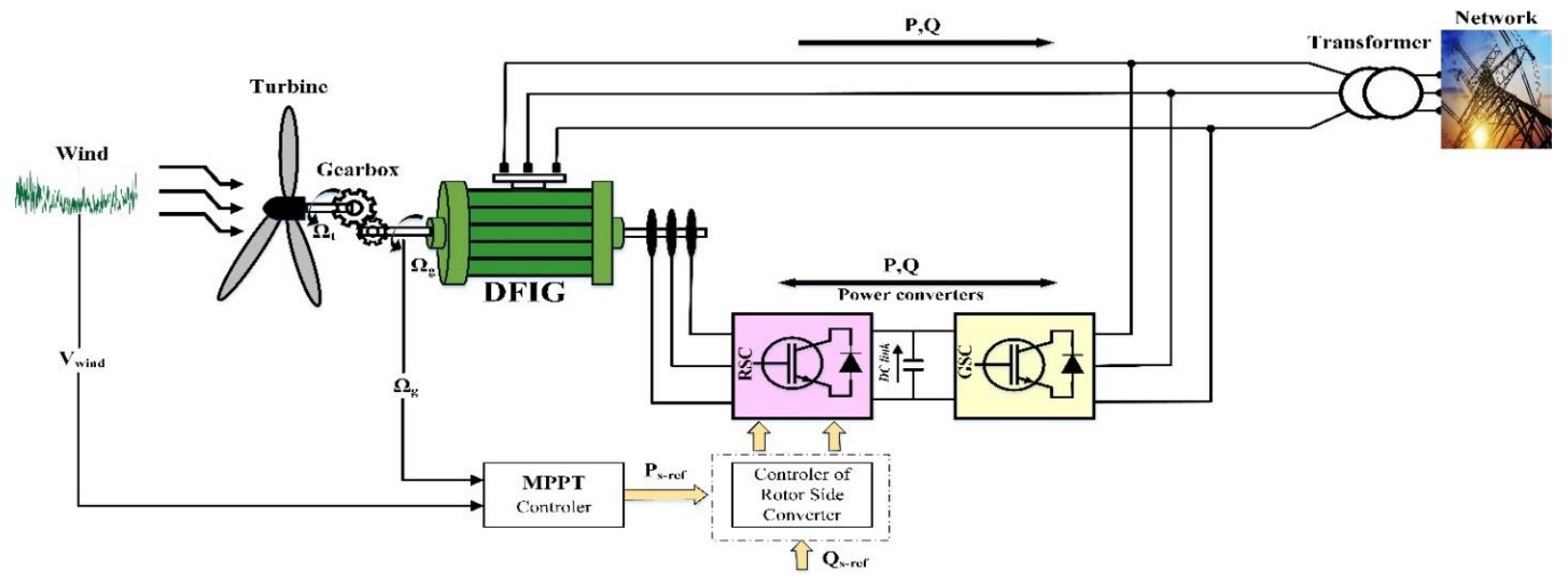

Figure. 1 The structure of the DFIG-based wind energy generation system

rotor. On the contrary, at the hyper-synchronous mode (the rotor speed is higher than the synchronous one), the electric energy is furnished from both the stator and the rotor. Also, depending on the wind speed, the DFIG operation can be classified into four zones [5]:

- Zone I: When the wind speed is not high enough to turn the wind turbine.

- Zone II: This zone is characterized by moderate wind speed. The pitch angle of the blade is equal to zero, and an MPPT block is implemented to capture the maximum electric power. Our work addresses this zone.

- Zone III: Now, the maximal power supported by the system is reached. Consequently, the blade pitch angle must be adjusted to maintain the safety of the DFIG.

- Zone IV: At this stage, the wind speed overpass the safety limit; it is no longer possible to keep the wind turbine running.

The primary popular control schemes of DFIG are vector control (VC), which consists of regulating separately rotor currents utilizing PI controllers [6], Direct Torque Control (DTC) and DPC strategy [7, 8]. These two latter methods take advantage of hysteresis comparators to regulate the active and reactive powers for DPC and the torque and the flux for DTC. Many difficulties have been related to VC, such as insufficient dynamic performances and the necessity of a Phase Locked-Loop (PLL) block [10]. In regards to conventional DPC, its main drawbacks are the significant power ripples and the noticeable variation of the switching frequency [11]. The same for DTC, considerable torque and flux ripples disturb the regular operation of the system [12]. Several attempts have been taken by researchers around the globe to improve these techniques. Among them, we mention the adaptive DPC [13] and the fuzzy DTC [14].

Recently, remarkable advances in nonlinear systems control theory have led to the design of sophisticated control schemes. Reference [15] presents a back-stepping controller for the Rotor Side Converter (RSC). Due to the sensitivity of this controller, an adaptive backstepping approach has been developed [16]. In parallel, a sliding mode controller (SMC) based DPC has been established for balanced and unbalanced grid conditions [17]. The robustness of the SMC against external disturbances and system parameter variations is guaranteed. However, the chattering phenomena hinder its hardware implementation.

More recently, the application of fractional calculus to engineering problems and systems control has attracted a lot of interest. Numerous papers have dealt with the design of fractional-order sliding mode controllers for various types of systems: Areal vehicles [18], robot manipulators [19], and ABS systems [20]. The problem that motivate this work is the design of a control strategy the can force the wind system to produce a high quality energy with the appropriate amount while guaranteeing the stability of the plant. The main drawbacks of the classical SMC are its high switching frequency that increases the harmonic pollution of the rotor current. Also, the chattering phenomena and its sensitivity to the system parameters' estimation. Unlike conventional SMC, the fractional-order one has a more substantial zone of stability and reduces the chattering effect [21]. All the results obtained in the aforementioned references have proven its robustness and high performance. Therefore, the FOSMC is very suitable to control the wind DFIG and to ensure the required performances.

The main contributions of this research paper are listed below: 
- The design of an improved and efficient FOSMC controller for DFIG based wind system.

- The achievement of high accuracy with the decrease of switching frequency.

- The enhancement of the power quality injected into the grid. follows:

The subsequent part of this paper is structured as

Section II deals with the modeling of the DFIG wind system. Section III describe the design methodology of the FOSMC controller. Section IV presents the simulation results obtained by comparing our proposal to several control techniques. Finally, section $\mathrm{V}$ draws conclusions and perspectives.

\section{Mathematical modeling of the DFIG based wind system}

The general structure of the DFIG wind energy conversion system is illustrated in Fig. 1. The mechanical part of the system is composed of the wind turbine and the gearbox. The electrical one is formed by the DFIG generator, which its stator is connected directly to the grid. At the same time, its rotor requires a back-to-back converter (RSC, the DC link, and the grid side converter GSC) to adapt the energy transfer back and forth between it and the network.

\subsection{The aerodynamic model of the wind turbine}

The total aerodynamic power acquired from the wind by the system can be expressed as follows [22]:

$$
\mathrm{P}_{\text {mec }}=\frac{1}{2} C_{P}(\lambda, \beta) \cdot \rho \cdot S \cdot V^{3}
$$

Where $\rho$ refers to the density of the air, $V$ is the wind speed. In contrast, $S$ designates the turbine swept area by the rotor blades, $C_{p}$ denotes the power coefficient of the wind turbine which is a nonlinear function of $\lambda$ (the tip speed ratio) and $\beta$ (the blade pitch angle).

The parameter $\lambda$ is defined by the following equation:

$$
\lambda=\frac{\mathrm{R} \Omega_{\mathrm{t}}}{\mathrm{V}}
$$

Where $\Omega_{t}$ and $R$ refer to the angular velocity of the DFIG's shaft and the turbine blade radius, respectively.

The power coefficient $C_{P}$ has several formulas $[23,24]$, one of them is considered at this stage:

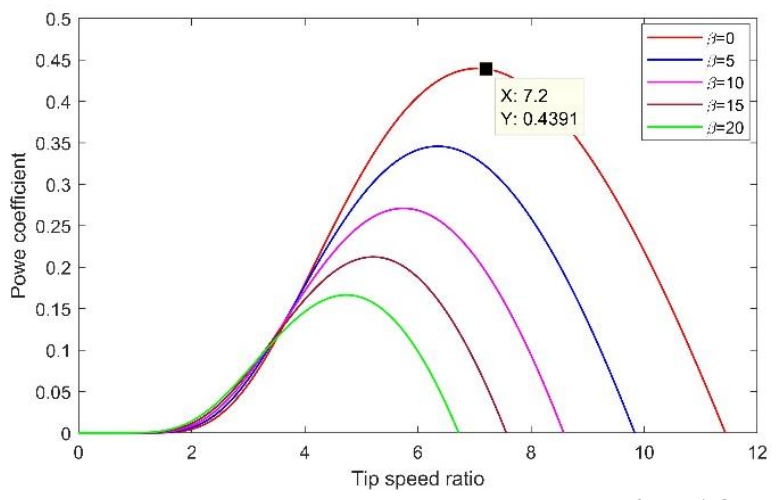

Figure. 2 The power coefficient $C_{p}$ versus $\lambda$ and $\beta$

$$
C_{P}(\lambda, \beta)=c_{1}\left(\frac{c_{2}}{\lambda_{i}}-c_{3} \beta-c_{4}\right) e^{\frac{-c_{5}}{\lambda_{i}}}+c_{6} \lambda
$$

With $c_{1}, c_{2}, c_{3}, c_{4}, c_{5}$ and $c_{6}$ are real constants.

The generator torque $T_{g}$ and speed $\Omega_{g}$ are given by the following formulas:

$$
\begin{aligned}
& T_{g}=\frac{1}{G} T_{t} \\
& \Omega_{t}=\frac{1}{G} G_{g}
\end{aligned}
$$

Where $G$ designate the gear ratio, $\Omega_{g}$ is the speed of the generator shaft, $T_{g}$ and $T_{t}$ are the generator torque and the turbine torque, respectively.

The turbine shaft dynamic can be simplified by the following expression:

$$
J \frac{d \Omega_{g}}{d t}=T_{g}-T_{e m}-f \Omega_{g}
$$

Where $T_{e m}$ indicates the magnetic torque and $f$ is the friction coefficient.

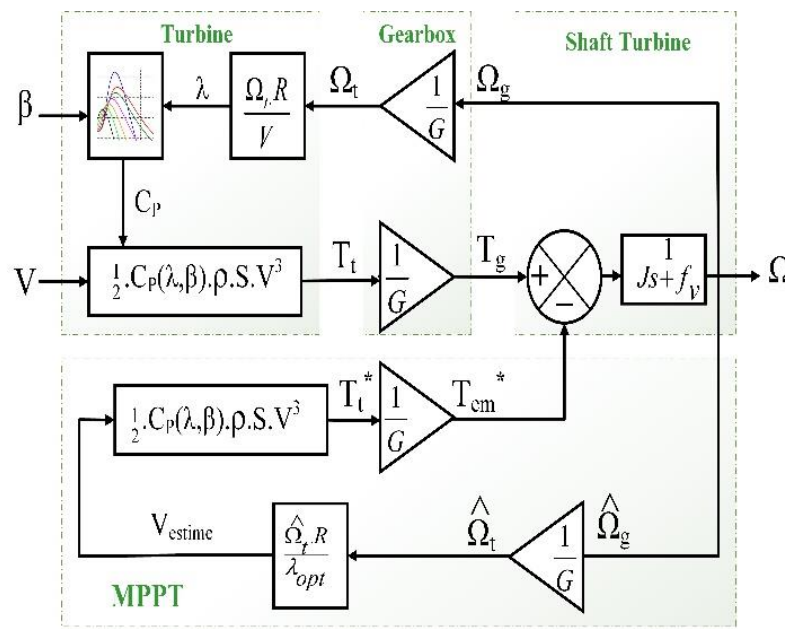

Figure. 3 Scheme of the MPPT algorithm 


\subsection{The MPPT strategy}

As mentioned before, when the generator operates in region II, it is compulsory to accommodate the rotor speed to extract the maximum power from the wind. The MPPT block ensures that the speed of the wind turbine corresponds to the maximum value of the power coefficient $\left(C_{P}=\right.$ 0.4391 ). It is achieved when $\lambda_{\text {opt }}=7.2$ and $\beta=0$ (Fig. 2). Fig. 3 exhibits the scheme of the adopted MPPT algorithm [15].

\subsection{The state space of the DFIG}

In this part, the objective is to develop the state model of DFIG from the electrical equations in the reference frame (d-q) [25]:

$$
\begin{aligned}
& V_{d s}=R_{s} i_{d s}+\frac{d \psi_{d s}}{d t}-\omega_{s} \psi_{q s} \\
& V_{q s}=R_{s} i_{q s}+\frac{d \psi_{q s}}{d t}-\omega_{s} \psi_{d s} \\
& V_{d r}=R_{r} i_{d r}+\frac{d \psi_{d r}}{d t}-\omega_{r} \psi_{q r} \\
& V_{q r}=R_{r} i_{q r}+\frac{d \psi_{q r}}{d t}-\omega_{r} \psi_{d r}
\end{aligned}
$$

Where:

$$
\begin{aligned}
& \psi_{d s}=L_{s} i_{d s}+M i_{d r} \\
& \psi_{q s}=L_{s} i_{q s}+M i_{q s} \\
& \psi_{d r}=L_{r} i_{d r}+M i_{d s} \\
& \psi_{q r}=L_{r} i_{q r}+M i_{q s}
\end{aligned}
$$

And: $\quad \omega_{r}=\omega_{s}-P \Omega_{g}$

where $i_{d s}$ and $i_{q s}$ are the stator current components, $V_{d s}$ and $V_{q s}$ designates respectively the stator voltage component in the d-q axis, $V_{d r}$ and $V_{q r}$ denotes the rotor voltage in the $\mathrm{d}-\mathrm{q}$ frame reference, $i_{d r}$ and $i_{q r}$ stands for the rotor current components, respectively, $P$ indicates the number of pole pairs of the stator windings, $\left(\psi_{d s}, \psi_{q s}\right)$ and $\left(\psi_{d r}, \psi_{d r}\right)$ are the stator and the rotor flux components, respectively, $\left(R_{S}, R_{r}\right)$ denominate the stator and rotor resistances, $\left(L_{s}, L_{r}, M\right)$ are the stator inductance, the rotor inductance and the magnetizing inductance, $\omega_{s}$ designate synchronous velocity.

The equivalent circuit of DFIG is shown in Fig. 4. By choosing the direct axis $d$ of the d-q reference aligned to the stator flux, the following holds [26]:

$$
\begin{gathered}
\psi_{q s}=0 \\
\psi_{d s}=\psi_{s}
\end{gathered}
$$

After neglecting the per phase stator resistance, the expression of the stator voltage becomes simpler. It is in advance by $\pi / 4$ to the stator flux vector [27]. Thus, we obtain:

$$
\begin{aligned}
& V_{d s}=0 \\
& V_{q s}=V_{s}=\varpi_{s} \psi_{s}
\end{aligned}
$$

Taking advantage of (10) and (11) by using them in (7) and (8) to find a new expression of the rotor voltages (12). Also, the original formulas of stator active and reactive power in the $\mathrm{d}-\mathrm{q}$ axis can be formulated otherwise, as shown in (12) [28].

$$
\left\{\begin{array}{c}
V_{d r}=R_{r} I_{d r}+\sigma L_{r} \frac{d}{d t} I_{d r}-\sigma L_{r} S \oplus_{s} I_{q r} \\
V_{q r}=R_{r} I_{q r}+\sigma L_{r} \frac{d}{d t} I_{q r}-\sigma S \Phi_{s} I_{d r}+S \frac{M V_{s}}{L_{s}}
\end{array}\right.
$$

$$
\left\{\begin{array}{c}
P_{s}=-\frac{M V_{s}}{L_{s}} I_{q r} \\
Q_{s}=\frac{V_{s}^{2}}{\omega_{s} L_{s}}-\frac{M V_{s}}{L_{s}} I_{d r} \\
T_{e m}=-P \frac{M V_{s}}{\omega_{s} L_{s}} I_{q r}
\end{array}\right.
$$

With: $\sigma=1-\left(M^{2} / L_{r} L_{s}\right)$ And $S$ is the slip ratio. The nonlinear state space model is given under the following form:

$$
\dot{X}=\mathrm{F}(X)+G U
$$

$$
\text { Where: }\left\{\begin{array}{c}
F(X)=\left(\begin{array}{c}
-\frac{R r}{\sigma L_{r}} I d r+S \oplus_{s} I_{q r} \\
-\frac{R_{r}}{\sigma L_{r}} I_{q r}-S \oplus_{S} I_{d r}+S \frac{M V_{S}}{\sigma L_{r} L_{S}}
\end{array}\right) \\
G=\left(\begin{array}{cc}
-\frac{R_{r}}{\sigma L_{r}} & 0 \\
0 & \frac{1}{\sigma L_{r}}
\end{array}\right) \\
X=\left(\begin{array}{l}
I_{d r} \\
I_{q r}
\end{array}\right), \quad U=\left(\begin{array}{l}
V_{d r} \\
V_{q r}
\end{array}\right)
\end{array}\right.
$$

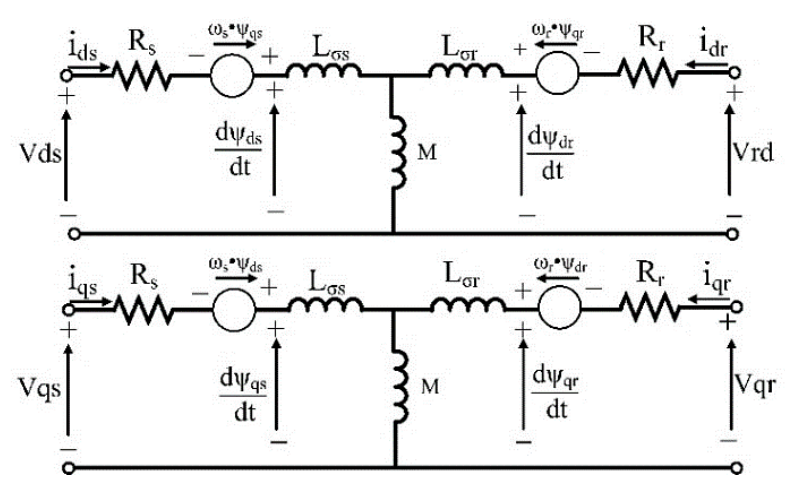

Figure. 4 The equivalent circuit of DFIG 
The objective of the control strategy is to ensure that the state variable $X$ tracks the reference trajectory $X_{\text {ref }}$ :

$$
X_{\text {ref }}=\left(\begin{array}{l}
I_{d r \_r e f} \\
I_{\text {qr_ref }}
\end{array}\right)
$$

Where:

$$
\left\{\begin{array}{c}
I_{d r_{-} r e f}=-\frac{L_{s}}{M V_{s}} P_{S_{-} r e f} \\
I_{d r_{-} r e f}=\frac{V_{s}}{\omega_{s} M}-\frac{L_{s}}{V_{s} M} Q_{S_{-} r e f}
\end{array}\right.
$$

We define the tracking errors by the following formula:

$$
e=\left(\begin{array}{l}
e_{1} \\
e_{2}
\end{array}\right)=\left(\begin{array}{l}
I_{d r_{r} r e f}-I_{d r} \\
I_{q r_{r e f}}-I_{q r}
\end{array}\right)
$$

\subsection{The simplified model of the voltage converter}

The back-to-back converter, used to control the bidirectional flow of energy, is formed of two IGBT based inverters. By assuming that the electronic switches are ideal, each two-level inverter can be represented by (19) [29].

$$
\left[\begin{array}{l}
V_{a n} \\
V_{b n} \\
c_{a n}
\end{array}\right]=\frac{U_{d c}}{3}\left[\begin{array}{ccc}
2 & -1 & -1 \\
-1 & 2 & -1 \\
-1 & -1 & 2
\end{array}\right]\left[\begin{array}{l}
S_{1} \\
S_{2} \\
S_{3}
\end{array}\right]
$$

Where $V_{a n}, V_{a n}$ and $V_{a n}$ denotes the simple voltages between the inverter output and the neutral (Fig. 5), $U_{D C}$ is the voltage at the DC link, $S_{1}, S_{2}$ and $S_{3}$ designate the switching signals that control the commutation cells.

Where $V_{a n}, V_{a n}$, and $V_{a n}$ denotes the simple voltages between the inverter output and the neutral (Fig. 5), $U_{D C}$ is the voltage at the DC link, $S_{1}, S_{2}$ and $S_{3}$ designate the switching signals that control the commutation cells.

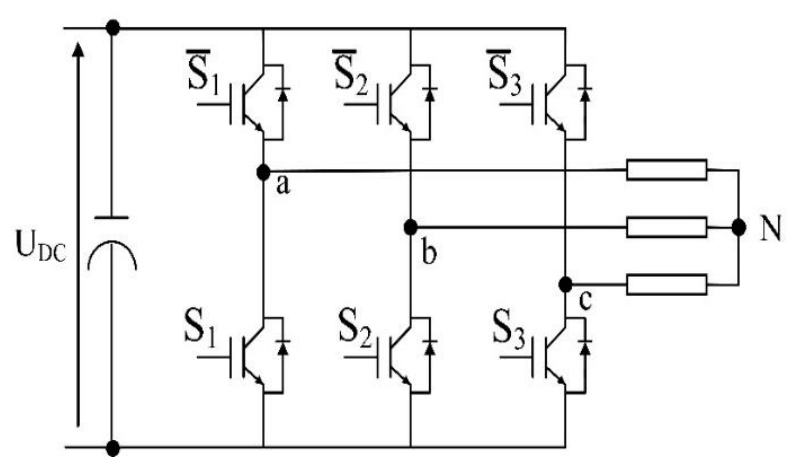

Figure. 5 Simplified topology of the two-level VSI

\section{The design of the FOSMC controller of RSC converter}

Before diving deep into the design of the controller, it is necessary to introduce some basics of the fractional order formalism.

\subsection{The fractional calculus concepts and basics}

The concept of Fractional-order calculus is a mathematical issue of more than 300 years old. It is no more than a generalization of integer differentiation and integration.

The continuous fractional order derivative and the integral operator can be described as follows:

$$
a D_{t}^{\alpha}= \begin{cases}\frac{d^{\alpha}}{d t^{\alpha}} & \text { for } \quad \alpha>0 \\ 1 & \text { for } \quad \alpha=0 \\ \int_{a}^{t}(d \tau)^{\alpha} & \text { for } \quad \alpha<0\end{cases}
$$

Where $a$ and $t$ indicate the limits of the operation and $\alpha$ denotes the order of the fractional operator (derivative or integration).

In general, there are three definitions of the fractional-order integro-differential operator which are well-known: They are enumerated as follows: the Grunwald-Letnikov or (G-L) definition, the Riemann-Liouville or simply (R-L) definition, and the Caputo definition [30].

Definition 1: The Riemann-Liouville fractional operator (derivative and integration) of order $\alpha$ applied to a function $\mathrm{f}$ is described as:

$$
\begin{gathered}
a D_{t}^{\alpha} f(t)=\frac{d^{\alpha}}{d t^{\alpha}} f(t)=\frac{1}{\Gamma(m-\alpha)} \frac{d^{m}}{d t^{m}} \int_{a}^{t} \frac{f(\tau)}{(t-\tau)^{\alpha-m+1}} d \tau \\
a D_{t}^{-\alpha} f(t)=I^{\alpha} f(t)=\frac{1}{\Gamma(\alpha)} \int_{a}^{t} \frac{f(\tau)}{(t-\tau)^{1-\alpha}} d \tau
\end{gathered}
$$

Here $\mathrm{m}$ is an integer that verify $-1<\alpha<m$ and $\Gamma$ represents the Gamma function.

Definition 2: The Caputo fractional derivative operator of order $\alpha$ applied to a continuous function is expressed as:

$$
a D_{t}^{\alpha} \simeq D^{\alpha}=\left\{\begin{array}{c}
\frac{1}{\Gamma(n-\alpha)} \int_{\alpha}^{t} \frac{f^{n}(\tau)}{(t-\tau)^{\alpha-n+1}} d \tau \\
\frac{d^{m}}{d t^{m}} f(t)
\end{array}\right.
$$

Definition 3: The GL definition of FO operator of order $\alpha$ applied to a function $f$ is given as: 


$$
\begin{gathered}
{ }_{a}^{G L} D_{t}^{\alpha} f(t)=\lim _{h \rightarrow 0} \frac{1}{h^{\alpha}} \sum_{j=0}^{\frac{t-\alpha}{h}}(-1)^{j}\left(\begin{array}{c}
\alpha \\
j
\end{array}\right)(t-j h)(24) \\
\left(\begin{array}{c}
\alpha \\
j
\end{array}\right)=\frac{\Gamma(\alpha+1)}{\Gamma(j+1) \Gamma(\alpha-j+1)}
\end{gathered}
$$

In order to simulate the fractional-order operator, the first step consists of obtaining its Laplace transform [20]:

$$
H(s)=S^{\alpha}, \alpha>0
$$

Then, a way to integrate expression (26) into a simulator is to approximate it by a transfer function [21]:

$$
H(s)=K \prod_{n=-N}^{N}\left(\frac{1+S / \oplus_{z, n}}{1+S / \oplus_{p, n}}\right), \alpha>0
$$

Where :

$$
\begin{aligned}
& \Phi_{z, n}=\Phi_{b}\left(\frac{\Phi_{h}}{\Phi_{b}}\right)^{\frac{n+N+\frac{1-\alpha}{2}}{2 N+1}} \\
& \varpi_{p, n}=\varsigma_{b}\left(\frac{\varpi_{h}}{\varpi_{b}}\right)^{\frac{n+N+\frac{1+\alpha}{2}}{2 N+1}} \\
& \varpi_{b} \oplus_{h}=1 \text { and } K=\oplus_{b}^{\alpha}
\end{aligned}
$$

With $K$ is a coefficient that calibrates the gain at $1 \mathrm{rd} / \mathrm{s}, \Phi_{p, n}$ and $\Phi_{z, n}$ are respectively poles and zeros, their numbers are calculated using $N, \omega_{b}$ and $\omega_{h}$ denote the upper and the lower bounds of the selected frequency interval of the approximation, respectively.

\subsection{The controller design}

The first key step in the design process of the
FOSMC controller of the RSC is the selection of an appropriate sliding surface. The proportional derivative fractional sliding surface is well known in the literature:

$$
S=k e+D^{\alpha} e
$$

Where $S$ designates the sliding surface and $k$ is a positive real coefficient.

The siding surface can be written as:

$$
S=\left(\begin{array}{l}
S_{1} \\
S_{1}
\end{array}\right)
$$

Where:

$$
S_{i}=k e_{i}+D^{\alpha} e_{i}
$$

\section{Theorem:}

Let us suppose that the DFIG is controlled by the following law:

$$
\begin{array}{r}
U=G^{-1}\left(-F(X)+\dot{X}_{r e f}+\frac{1}{k}\left(D^{\alpha+1} e+\right.\right. \\
\zeta \operatorname{sign}(S)))
\end{array}
$$

Where: $\zeta=\left(\begin{array}{cc}\zeta_{1} & 0 \\ 0 & \zeta_{2}\end{array}\right)$ with $\zeta_{1}$ and $\zeta_{2}$ are real positive coefficients.

Hence, the closed-loop state model of the DFIG is asymptotically stable, and the active and reactive powers track their reference values.

\section{Proof:}

We begin the demonstration by choosing the following quadratic Lyapunov function:

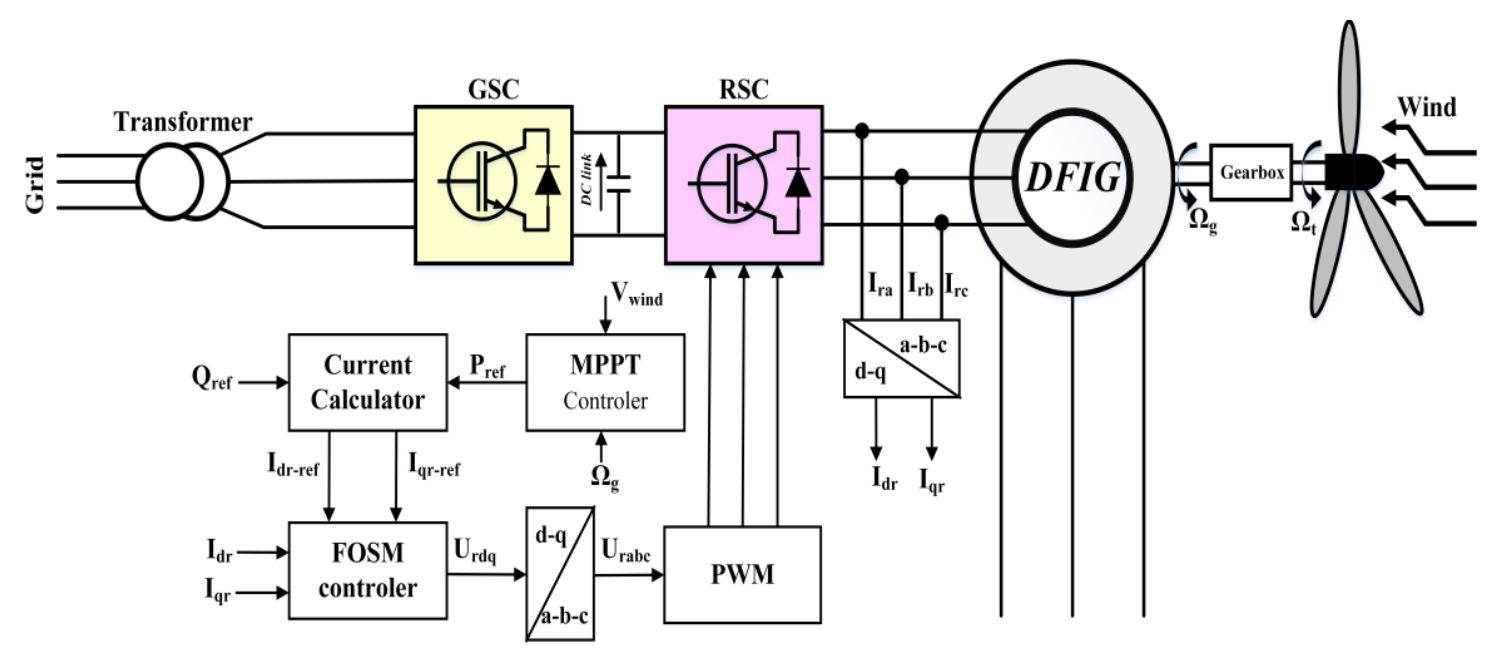

Figure. 6 Scheme of the control strategy of the RSC converter 


$$
V=\frac{1}{2} S^{T} S
$$

Taking the time derivative of Eq. (30) on both sides yields:

$$
\dot{V}=S^{T} \dot{S}
$$

We have:

$$
\dot{S}=k \dot{e}+D^{\alpha+1} e
$$

After replacement, Eq. (32) becomes:

$$
\dot{S}=k\left(\dot{X}_{\text {ref }}-F(X)-G U\right)+D^{\alpha+1} e
$$

Plugging (29) into (33) leads:

$$
\dot{S}=-\zeta \operatorname{sign}(S)
$$

As a result:

$$
\dot{V}=-S^{T} \zeta \operatorname{sign}(S)
$$

After simplification, we obtain:

$$
\dot{V}=-\left(\zeta_{1}\left|S_{1}\right|+\zeta_{2}\left|S_{2}\right|\right) \leq 0
$$

According to the Lyapunov theorem our system is asymptotically stable under the control law (29). Fig. 6 shows the diagram of the proposed DPC based FOSMC strategy for the RSC converter.

\section{Simulation results}

This section aims to show the high performances and the robustness of our technique through the obtained numerical results. The proposed approach has been implemented as well as the other parts of the system. The whole model is simulander MATLAB/SIMULINK. We drive two tests; the first Table 1. Parameters of the DFIG based wind system

\begin{tabular}{l|c}
\hline Parameter & Value \\
\hline Rated power & $P_{n}=7.5 \mathrm{KW}$ \\
& $\rho=1.22 \mathrm{Kg} \cdot \mathrm{m}^{-3}$ \\
Air density & $G=5.4$ \\
Gearbox ratio & $f=0.00673 \mathrm{~N} . \mathrm{m} . \mathrm{s}^{-1}$ \\
Viscous friction coefficient & $j=0.3125 \mathrm{~kg} \cdot \mathrm{m}^{2}$ \\
Moment of inertia & $F=50 \mathrm{~Hz}$ \\
Rated frequency & $R_{r}=0.455 \Omega$ \\
Rotor resistance & $R_{s}=0.62 \Omega$ \\
Stator resistance & $L_{r}=0.081 \mathrm{H}$ \\
Rotor inductance & $L_{s}=0.084 \mathrm{H}$ \\
Stator inductance & $M=0.078[\mathrm{H}]$ \\
Mutual inductance & $P=2$ \\
Number of pair of poles & \multicolumn{1}{c}{$P=2$} \\
\hline
\end{tabular}

International Journal of Intelligent Engineering and Systems, Vol.14, No.2, 2021

\subsection{First test}

one intends to describe how the system outputs tracks precisely their reference values and assesses the quality of the power injected into the grid, whereas the second one studies the system under parameter variations to demonstrate the robustness of our proposal. The two simulation tests involve a DFIG of $7.5 \mathrm{KW}$. Its parameter values are summarized in Table 1.

In this case, the system used in the simulation is ideal. No parameter uncertainties are considered. We selected a variable wind speed profile in order to make the study similar to realistic conditions. Also, it allows evaluating the dynamic performances of the proposed control scheme. According to Fig. 7, the wind speed varies between $6 \mathrm{~m} / \mathrm{s}$ and $12 \mathrm{~m} / \mathrm{s}$.

Fig. 8 displays the evolution of active power versus the simulation time. The measured active power tracks the reference one accurately. In addition, given the thickness of the curve, we notice that the chattering effect that accompanies the integer sliding mode control has been reduced drastically. In other words, the proposed method ensures a significant attenuation of the power ripples. Fig. 9 and Fig. 10 shows that the reactive power and the electromagnetic torque reach the desired value rapidly and track it during the entire simulation

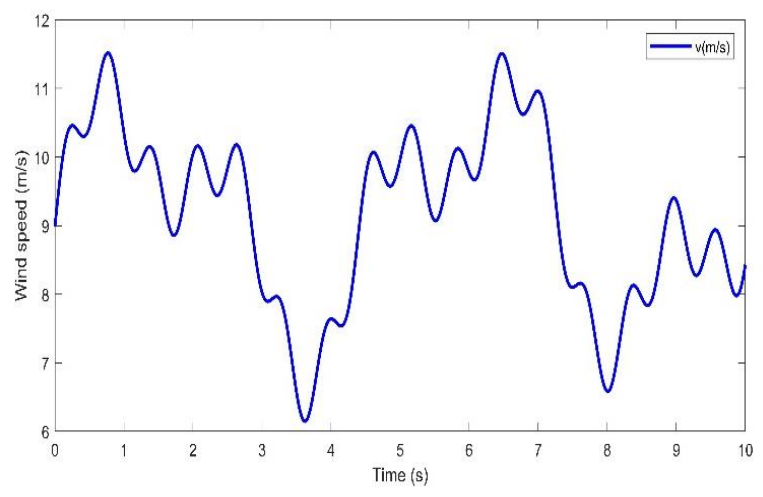

Figure. 7 The wind speed profile $(\mathrm{m} / \mathrm{s})$

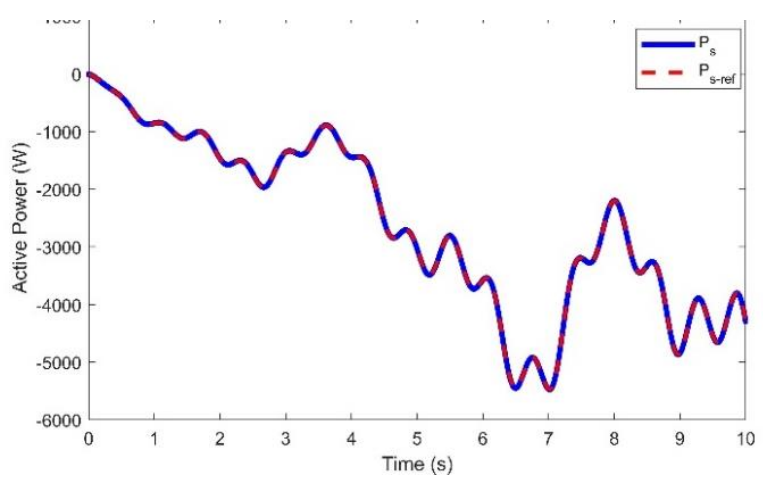

Figure. 8 The active power and its reference (W) 


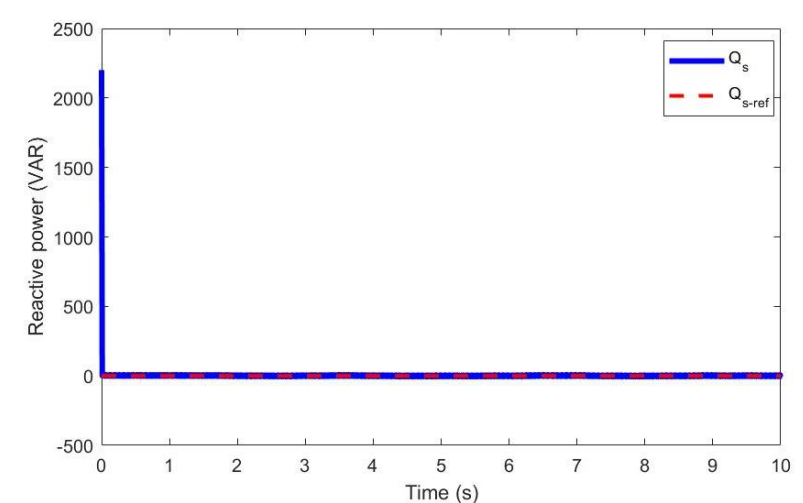

Figure. 9 The reactive power and its reference (VAR)

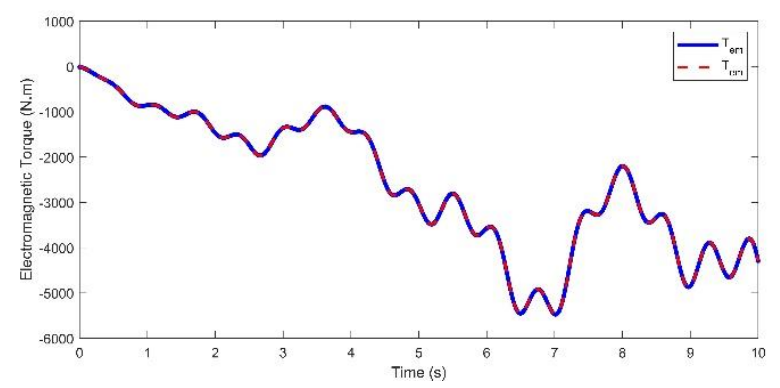

Figure. 10 The electromagnetic torque and its reference

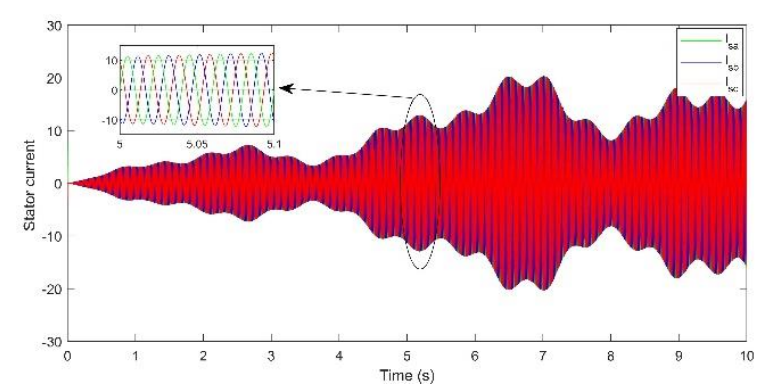

Figure. 11 The stator current (A)

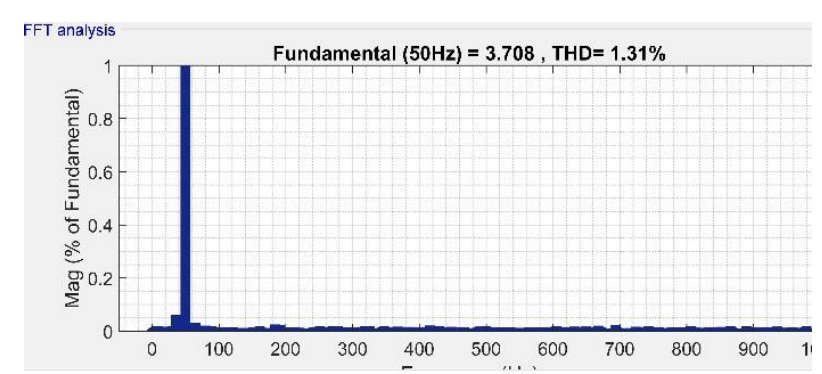

Figure. 12 The THD of stator current using a step wind speed profile

period. Meanwhile, the power and torque ripples are almost neglected in a way that both curves appear virtually identical.

Fig. 11 illustrates the shape of the stator currents injected into the electrical grid.

Zoom on the graph shows that these currents have practically a sinusoidal waveform of a frequency equal to $50 \mathrm{~Hz}$.

In order to judge the quality of the electrical power poured into the grid by the DFIG generator we need to calculate the THD (Total harmonic distortion) of the stator current, which is given by the following formula:

$$
\operatorname{THD}(\%)=100 \frac{\sqrt{\sum_{H=2}^{\infty} I_{H}^{2}}}{I_{F}}
$$

$I_{H}$ is the RMS (Root Mean Square) value of the current harmonic of order $\mathrm{H}, I_{F}$ designates the RMS (Root Mean Square) value of the fundamental component of the stator current .

To comply with the recommendations of international standards, the THD must be reduced as much as possible. The harmonic pollution of the power injected into the grid has a harmful effect on the protection equipment and clients' appliances. According to Fig. 12 , THD $=1,31 \%$, which confirms that the energy generated is clean and respects the standards.

\subsection{The test of robustness (second test)}

In this part, we vary the values of the rotor resistance and inductance to prove the robustness of the FOSMC controller. In real applications these parameters may change during the system running due to temperature variation or frequency effects such as skin and proximity effects. During the second simulation test the rotor inductance and resistance values are chosen as follows:

$$
\begin{aligned}
& \triangle R_{r}=120 \% R_{r} \\
& \triangle L_{r}=120 \% L_{r}
\end{aligned}
$$

From Fig. 13 and Fig. 14, we notice that even though the parameters variations, the active power error decay to zero and the stability of the system is guaranteed. The same remark is applied to reactive power. It is underlined that the parameter uncertainties do not alter the stability and the accuracy of our control strategy. These results demonstrate the robustness of the FOSMC based DPC.

\subsection{The test of robustness (Second test)}

To highlight the efficiency of our method, a comparison with the existing FOSMC technique has been performed. The design of the FOSMC controller is described in [18]. Fig. 17 and Fig. 18 illustrate respectively the simulation results corresponding to 


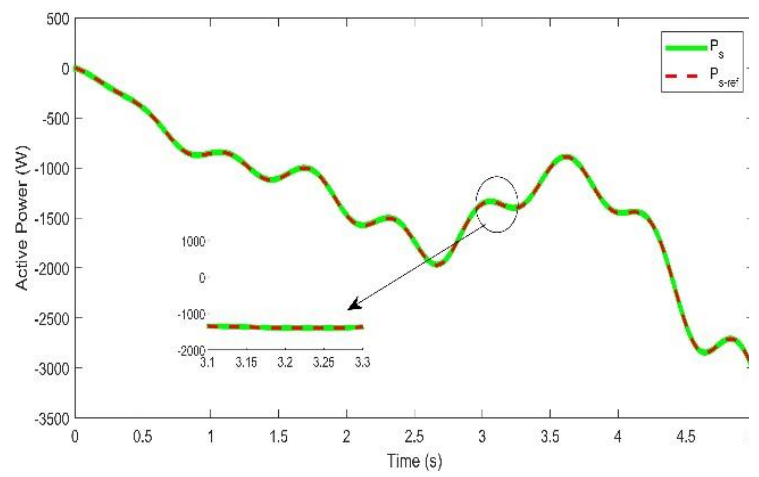

Figure. 13 The active power of the second test $(\triangle$ $\left.R_{r}=120 \% R_{r}\right)(\mathrm{W})$

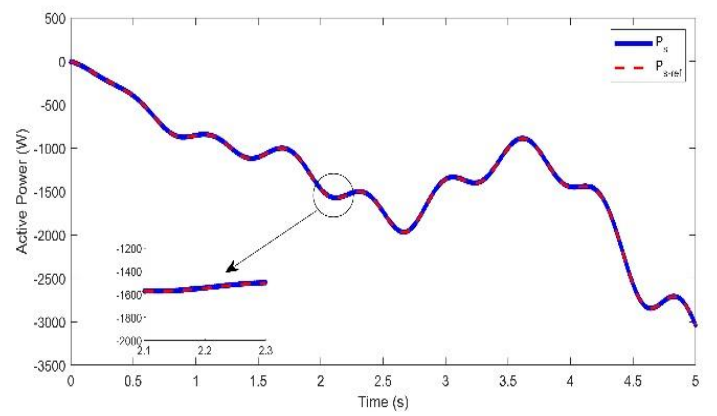

Figure. 14 The active power of the second test $\left(\triangle L_{r}=\right.$ $\left.120 \% L_{r}\right)(\mathrm{W})$

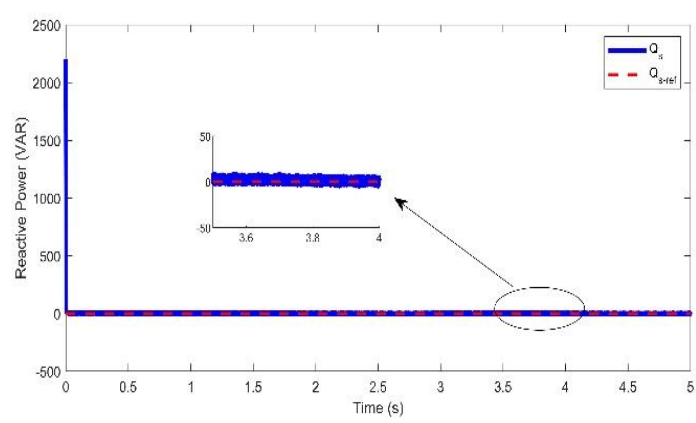

Figure. 15 The reactive power of the second test $(\triangle$ $\left.R_{r}=120 \% R_{r}\right)(\mathrm{VAR})$

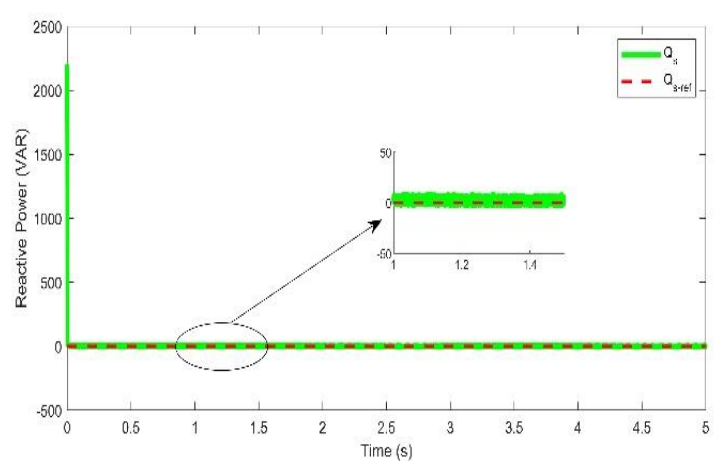

Figure. 16 The reactive power of the second test $\left(\triangle L_{r}=120 \% L_{r}\right)(\mathrm{VAR})$

active and reactive power. From this result, we observe the difference between the two controllers. The technique proposed in this work increase the accuracy and the rapidity of the system response

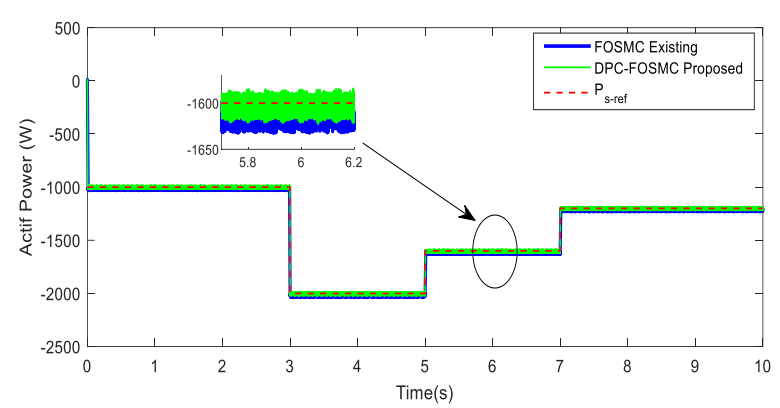

Figure. 17 Stator active power of DFIG

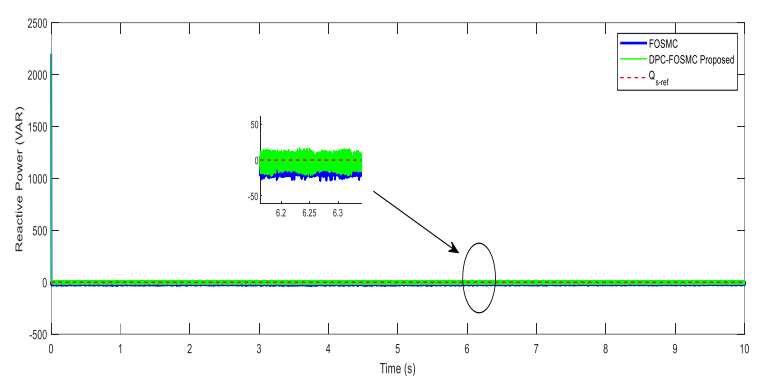

Figure. 18 Stator reactive power of DFIG

when compared to the existing FOSMC.

\subsection{Comparison to other methods in the literature}

After we proved the rapidity, precision, and robustness of the proposed controller, it is interesting to compare it with similar techniques in the literature to demonstrate its advantages and superiority. It is underlined here that the aforementioned techniques are not made under the same constraints and conditions, it is very rare to find many works done under similar conditions. Based on this comparison, the proposed solution of the FOSMC-DPC has a Low Power ripple and then that obtained with the Field Oriented Control of a DFIG in N. El Ouanjli (2017) [32]. Thus, the Backstepping control presented by S. Mensou (2020) [15] has Moderate-low Power ripples than our Technical. Furthermore, the proposed solution is robust, and the total harmonic distortion (THD) has excellent quality with the Backstepping and Field Oriented Control. Table 2 resumes the performance characteristics of recently published controllers and our proposal. Based on this comparison, the superiority of the FOSMC-DPC is proved.

\section{Conclusion}

In this study, comprehensive modeling of the DFIG based wind system has been presented. Then, the design of a FOSMC controller for DFIG has been proposed. The synthesis of the fractional derivatives has been achieved by using the CRONE approximation. Also, the stability of the system is 
Table 2. The comparison between our results and other methods published

\begin{tabular}{|c|c|c|c|c|}
\hline $\begin{array}{c}\text { Publication } \\
\text { paper }\end{array}$ & Technic methods & Power ripples & $\begin{array}{c}\text { THD of the } \\
\text { current grid (\%) }\end{array}$ & Robustness \\
\hline $\begin{array}{c}\text { N. El Ouanjli } \\
\text { (2019) [32] }\end{array}$ & FOC used PI & High & 11.17 & Not robust \\
\hline $\begin{array}{c}\text { S. Mensou } \\
\text { (2019) [5] }\end{array}$ & Backstepping & Moderate-low & 4.52 & Robust \\
\hline $\begin{array}{c}\text { N. El Ouanjli } \\
\text { (2019) [32] }\end{array}$ & Fuzzy Logic & Low & 2.81 & Robust \\
\hline $\begin{array}{c}\text { Our Proposed } \\
\text { technique }\end{array}$ & FOSMC-DPC & Low & 1.31 & Robust \\
\hline
\end{tabular}

ensured through the Lyapunov theorem. After that, several simulation tests have been established, including parameter variations.

The main contributions of this study as follows:

- The nonlinear FOSMC-DPC strategy provides High performance with different wind profiles to a wind energy conversion system.

- The Simulation results obtained demonstrate the better tracking performances and Low Power ripples of the system, which ensures the effectiveness and robustness of the FOSMC-DPC controller.

- It should be noted that the FOSMC Proposed offers a low Total Harmonic Distortion $(\mathrm{THD}=1.91 \%)$ when compared to the existed methods, our approach comply with the limit of 5\% prescribed by the IEEE-519 standard.

The topic of our future research may include the development of an adaptive FOSMC controller for DFIG and the hardware implementation of the proposed controller.

\section{Conflicts of Interest}

The authors declare that they have no conflict of interest

\section{Acknowledgments}

MAB and HELMO performed the study of DPCFOSMC strategies and the structure of the paper. MAB modeled the proposed. WECS under MATLAB/SIMULINK. MAB and HELMO wrote the paper. HELMO, TL and HELMA contributed to reviewing the paper. HELMO, TL and HELMA contributed to reviewing the paper. All authors read and approved the final manuscript.

\section{References}

[1] O. Zamzoum, A. Derouich, S. Motahhir, Y. El Mourabit, A. El Ghzizal, "Performance analysis of a robust adaptive fuzzy logic controller for wind turbine power limitation", Journal of Cleaner Production, Vol. 265, pp. 121659, 2020.

[2] I. Tizgui, H. Bouzahir, E. Guezar, and B. Benaid, "Estimation of electricity production for a Moroccan wind farm", In: Proc. of 2016 5th International Conf. on Electronic Devices, Systems and Applications (ICEDSA), Ras $\mathrm{Al}$ Khaimah, pp. 1-4, 2016.

[3] M. Rostami, S. M. Madani and, S. Ademi, "Sensorless Closed-Loop Voltage and Frequency Control of Stand-Alone DFIGs Introducing Direct Flux-Vector Control", in IEEE Transactions on Industrial Electronics, Vol.67, No. 7, pp. 6078-6088, 2020.

[4] Z. Dekali, L. Baghli, A. Boumediene, and M. Djemai, "Control of a Grid Connected DFIG Based Wind Turbine Emulator", 2018 5th International Symposium on EnvironmentFriendly Energies and Applications (EFEA), Rome, pp. 1-6, 2018.

[5] S. Rhaili, A. Abbou, S. Marhraoui, R. Moutchou, and N. Hichami, "Robust Sliding Mode Control with Five Sliding Surfaces of Five-Phase PMSG Based Variable Speed Wind Energy Conversion System", International Journal of Intelligent Engineering and Systems, Vol. 13, No. 4, pp. 346-357, 2020.

[6] E. Aydin, A. Polat, and L. T. Ergene, "Vector control of DFIG in wind power applications", In: Proc. of 2016 IEEE International Conf. on Renewable Energy Research and Applications (ICRERA), Birmingham, pp. 478-483, 2016.

[7] M. Taleb, M. E. Haroussi, and A. Ba-Razzouk, "Improved Direct Torque Control of a Doubly Fed Induction Generator in a Wind Energy 
Conversion System", In: Proc. of 6th International Renewable and Sustainable Energy Conf. (IRSEC), Rabat, Morocco, pp. 1-6, 2018.

[8] M. A. Mossa and S. Bolognani, "High performance Direct Power Control for a doubly fed induction generator", In: Proc. of IECON 2016 - 42nd Annual Conf. of the IEEE Industrial Electronics Society, Florence, pp. 1930-1935, 2016.

[9] A. Mehdi, A. Reama, H. E. Medouce, S. E. Rezgui, and H. Benalla, "Direct active and reactive power control of DFIG based wind energy conversion system", 2014 International Symposium on Power Electronics, Electrical Drives, Automation and Motion, Ischia, 2014.

[10] D. Sun, X. Wang, H. Nian, and Z. Q. Zhu, "A Sliding-Mode Direct Power Control Strategy for DFIG Under Both Balanced and Unbalanced Grid Conditions Using Extended Active Power", in IEEE Transactions on Power Electronics, Vol. 33, No. 2, pp. 1313-1322, 2018.

[11] H. Nian, Y. Song, P. Zhou, and Y. He, "Improved Direct Power Control of a Wind Turbine Driven Doubly Fed Induction Generator During Transient Grid Voltage Unbalance", in IEEE Transactions on Energy Conversion, Vol. 26, No. 3, pp. 976-986, 2011.

[12] Y. Li1, L. Hang, G. Li1, Y. Guo, Y. Zou, J. Chen, J. Li, J. Zhuang and, S. Li "An improved DTC controller for DFIG-based wind generation system", In: Proc. of 2016 IEEE 8th International Power Electronics and Motion Control Conf. (IPEMC-ECCE), Asia, Hefei, pp. 1423-1426, 2016.

[13] F. Mazouz, S. Belkacem, I. Colak, S. Drid, and Y. Harbouche, "Adaptive direct power control for double fed induction generator used in wind turbine", Electrical Power and Energy Systems, Vol. 114, 2020.

[14] W. Ayrir, M. Ourahou, B. El Hassouni, and A. Haddi, "Direct torque control improvement of a variable speed DFIG based on a fuzzy inference system", Mathematics and Computers in Simulation, Vol. 167, pp. 308-324, 2020.

[15] S. Mensou, A. Essadki, T. Nasser, B. B. Idrissi, and L. B. Tarla, "Dspace DS1104 implementation of a robust nonlinear controller applied for DFIG driven by wind turbine", Renewable Energy, Vol. 147, pp. 1759-1771, 2020.

[16] B. Bossoufi, M. Karim, A. Lagrioui, M. Taoussi, and A. Derouich, "Observer backstepping control of DFIG-Generators for wind turbines variable-speed: FPGA-based implementation", Renewable Energy, Vol. 81, pp. 903-917, 2015.

[17] A. Kadri, H. Marzougui, and F. Bacha, "Improved SMC Approach for Rotor-Side Converter of DFIG-Based on Stator Flux Estimator Using a Programmable Low Pass Filter", 2019 6th International Conf. on Control, Decision and Information Technologies (CoDIT), Paris, France, pp. 2027-2032, 2019.

[18] M. Labbadi, S. Nassiri, L. Bousselamti, M. Bahij and M. Cherkaoui, "Fractional-order Fast Terminal Sliding Mode Control of Uncertain Quadrotor UAV with Time-varying Disturbances", 2019 8th International Conf. on Systems and Control (ICSC), Marrakesh, Morocco, pp. 417-422, 2019.

[19] H. Komijani, M. Masoumnezhad, M. M. Zanjireh, and M. Mir, "Robust Hybrid Fractional Order Proportional Derivative Sliding Mode Controller for Robot Manipulator Based on Extended Grey Wolf Optimizer", Robotica, Vol.38, No. 4, pp. 605-616, 2020.

[20] S. S. Moosapour, S. B Fazeli Asl, and M. Azizi, "Adaptive fractional order fast terminal dynamic sliding mode controller design for antilock braking system (ABS)", Int. J. Dynam Control, Vol. 7, pp. 368-378, 2019.

[21] F. M. Zaihidee, S. Mekhilef, and M. Mubin, "Robust speed control of PMSM using sliding mode control (SMC) - A review", Energies, Vol. 12, No. 9, p. 1669, 2019.

[22] D. Hammoumi, C. El Bekkali, M. Karim, M. Taoussi, N. El Ouanjli, and B. Bossoufi, "Direct controls for wind turbine with PMSG used on the real wind profile of Essaouira-Morocco city", Indonesian Journal of Electrical Engineering and Computer Science, Vol. 16, No. 3, pp. 12291239, 2019.

[23] R. Melício, V. M. F. Mendes and, J. P. S. Catalão, "Fractional-order control and simulation of wind energy systems with PMSG/full-power converter topology", Energy Conversion and Management, Vol. 51, No. 6, pp. 1250-1258, june 2010.

[24] A. Djoudi, S. Bacha, H. Chekireb, E. M. Berkouk. Benbouzid, and J. Sandraz, "Robust stator currents sensorless control of stator powers for wind generator based on DFIG and matrix converter", Electrical Engineering, Vol. 99, pp. 1043-1051, 2017.

[25] R. Chakib, A. Essadki, and M. Cherkaoui "Modeling and control of a wind system based on a DFIG by active disturbance rejection control", International Review on Modeling and Simulations, Vol.7, No.4, pp. 626-637, 2014. 
[26] B. Hopfensperger, D. J. Atkinson and, R. A. Lakin, "Stator-flux-oriented control of a doublyfed induction machine with and without position encoder", In: Proc. of IEE - Electric Power Applications, Vol. 147, No. 4, pp. 241-250, 2000

[27] J. Hu, Y. Huang, D. Wang, H. Yuan, and X. Yuan, "Modeling of gridconnected DFIG-based wind turbines for DC-link voltage stability analysis", IEEE Trans. Sustainable Energy, Vol. 6, No.4, pp. 1325-1336, 2015.

[28] Y. Ihedrane, C. El Bekkali, M. El Ghamrasni, S. Mensou, and B. Bossoufi "Improved wind system using non-linear power control", Indonesian Journal of Electrical Engineering and Computer Science, Vol. 14, No. 3, pp. 11481158, 2019.

[29] O. Zamzoum, Y. El Mourabit, M. Errouha, A. Derouich, and A. El Ghzizal, "Active and Reactive Power Control of Wind Turbine based on Doubly Fed Induction Generator using Adaptive Sliding Mode Approach", International Journal of Advanced Computer Science and Applications(IJACSA), Vol.10, No. 2, pp. 397-406, 2019.

[30] M. P. Aghababa, "A Lyapunov-based control scheme for robust stabilization of fractional chaotic systems", NonlinearDyn, Vol. 78, No. 3, pp. 2129-2140, 2014.

[31] K. D. E. Kerrouche, L. Wang, A. Mezouar, L. Boumediene, and A. Van Den Bossche "Fractional-Order Sliding Mode Control for DSTATCOM Connected Wind Farm Based DFIG Under Voltage Unbalanced", Arabian Journal for Science and Engineering, Vol. 44, pp. 22652280, 2019.

[32] N. El Ouanjli, S. Motahhir, A. Derouich, A. El Ghzizal, A. Chebabhi, and M. Taoussi "Improved DTC strategy of doubly fed induction motor using fuzzy logic controller", Energy Reports, Vol. 5, pp. 271-279, 2019.

[33] L. Xiong, J. Wang, X. Mi, and M. W. Khan, "Fractional order sliding mode based direct power control of grid-connected DFIG", IEEE Trans. Power Systems., Vol. 33, No. 3, pp. 3087-3096, 2017 